\title{
Power Quality Improvement in Grid from Wind Turbine by using Shunt Hybrid Active Filter
}

\author{
Naveen Kumar.D, Anagandula Naresh, Vangala Sandeepreddy, Vindyala Balakrishna
}

\begin{abstract}
This paper provides Frame D-Q Synchronous Reference Frame (SRF) current manipulate technique for generating a reference present day that's required for 3-phase four-twine electric hybrid shunt hybrid active power filter (SHAPF) to resolve the hassle of harmonics in the power device community. Here, the passive factors SHAPF has beenused for reactive strength reimbursement and to eliminate the decrease order harmonics and lively parts have been used for the higher harmonics. A modified phase lock loop (PLL) has been used to address multiple frequency elements of non-perfect voltage. All simulations to attain the purpose that has been achieved in the MATLAB / SIMULINK for best conditions and unbalanced electrical voltage. From the simulation results have shown that the implementation of the proposed $D-Q S R F$ SHAPF based THD result in a reduction in community electricity systems in both the balanced and unbalanced situations.
\end{abstract}

Keywords- Phase Lock Loop, PI controller, SRF, THD, SHAPF

\section{INTRODUCTION}

A thorough manage of a breeze turbine framework related to a mechanical plant is tested in this paper where a calculation has been created permitting a manipulate structure that makes use of an inverter associated with the matrix facet, to infuse the on hand power, just as to fill in as a functioning force channel, moderating burden modern-day unsettling influences and upgrading power first-rate. This paper gives Synchronous Reference Frame (SRF) current manipulate approach so one can produce the essential reference cutting-edge for 3-level shunt half of and half dynamic electricity channel (SHAPF) to address song problem in control framework arrange. Here, the uninvolved components of SHAPF were utilized for pay of responsive strength and to dispense with the decrease request track and the dynamic part were utilized for the better request music. All the duplicate for carrying out the goal has been led in MATLAB/SIMULINK condition for best and uneven mains voltage situations.

\section{Writing Survey}

The extensive usage of nonlinear hundreds in family, business, mechanical place reasons control fine issues, for

Revised Manuscript Received on September 14, 2019.

Naveen Kumar.D, Assoc Professor, , Department of EEE, Siddhartha Institute of Technology \& Sciences, Narapally, Ghatkesar, Hyderabad, Telangana, India

Anagandula Naresh, Assist. Prof, Department of EEE, Siddhartha Institute of Technology \& Sciences, Narapally, Ghatkesar, Hyderabad, Telangana, India

Vangala Sandeepreddy, Assist. Prof, Department of EEE, Siddhartha Institute of Technology \& Sciences, Narapally, Ghatkesar, Hyderabad, Telangana, India

Vindyala Balakrishna, Professor, Department of EEE, Siddhartha Institute of Technology \& Sciences, Narapally, Ghatkesar, Hyderabad, Telangana, India. instance, symphonious modern-day, bad power thing, unbalance, voltage slump and develop, responsive energy trouble and so forth. A part of the times of nonlinear burdens are uncontrolled and managed rectifiers; variable velocity drives Alternating Current and Direct Current continuous strength elements, round phase heaters, electronic counterweight, and programmable motive controllers and so forth. Every this sort of devices are low cost, adaptable and power productive, they'll weaken manipulate excellent by using infusing symphonious cutting-edge into the energy framework and expending unreasonable responsive strength, as they are drawing nonsinusoidal contemporary from utilities. These wonders can reason severa troubles, for example, reverberation, inordinate nonpartisan flows, low electricity thing and so forth. In a slicing edge control framework, increasing of burdens and non-straight hardware's had been inquiring for the remuneration of the unsettling affects brought on for them. These nonlinear burdens may purpose bad electricity factor and high level of tune. Dynamic energy channel innovation is the most effective approach to make up for responsive strength and drop decrease sounds created with the aid of nonlinear burdens. The inactive tuned channel may be applied to provide a low impedance way to floor for symphonious signal. Along these lines, for wiping out unique consonant elements, singular channels are added. This makes the plan and coordination of detached channels convoluted. Likewise the plausibility of arrangement sounds, massive length and so forth makes the inactive channel much less attractive. Consequently we pass for mixture dynamic energy channel which has joined qualities of both dynamic and indifferent power channels.

\section{Requirement For Power Compensation}

The vast consonant sources incorporate PC, TV, and PC control elements to the strength converters applied in ventures. Every any such items utilize a few form of depth alternate, as an example, aircon to air conditioning, air con to $\mathrm{dc}, \mathrm{dc}$ to $\mathrm{dc}$, or dc to air con, strikingly these new age equipment's are regularly delicate to control high-quality troubles, as an example, song. Furthermore these track makes exclusive negative affects in the power framework. Increasingly over the clients are transforming into increasingly more mindful approximately the budgetary outcomes of the power high-quality troubles, as an example, sounds, receptive strength, homeless human beings and so on. Henceforth it receives essential for the customers just because the utilities to restrict the consonant contortion and responsive strength utilization to least. One of the solutions 
for restriction the symphonious twisting and electricity aspect adjustment is the usage of channels.

\section{Cross breed Active Power Filter}

The pass breed dynamic energy channel is handiest the arrangement blend of dynamic energy channel and the latent additives. The tune in the energy framework may be expelled in the accompanying manners.

By giving a low impedance manner to ground for consonant sign.

$\square \quad$ By infusing remunerating indicators which can be in degree resistance with the symphonious signal present inside the framework.

- $\quad$ For the primary we will make use of latent tuned channel and for the final dynamic channel may be applied.

- Active channel is related in arrangement with the uninvolved channel through a coupling transformer.

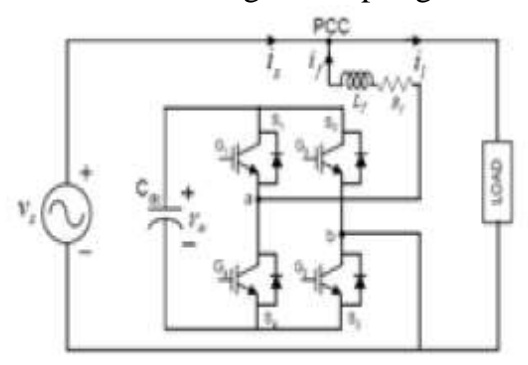

Figure 1: PWM VSI Unit

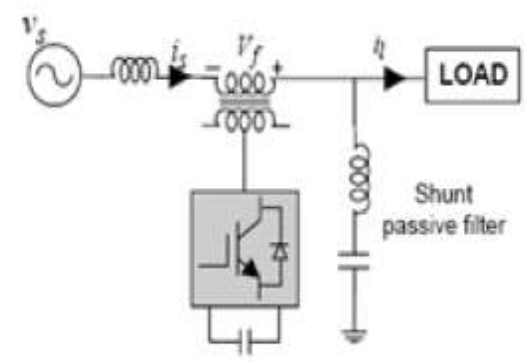

Figure 2: Hybrid Active Power Filter

\section{ACTIVE POWER FILTER}

The primary concept of lively electricity filter is that, current or voltage harmonics can be eliminated by means of injecting the identical harmonic additives of the current or voltage with identical significance and opposite in section. This idea can be applied the usage of power electronic switches along with IGBT, and MOSFET and advanced microcontrollers. Apart from the harmonic repayment, active strength clear out can offer the necessary reactive strength to the burden. Thus, active

energy filter can compensate various harmonic components and on the identical time improve the electricity thing at the moment. The fundamental feature of an active energy filter may be summarized as,

- Harmonic repayment, harmonic isolation, damping harmonic and harmonious Termination.

- reactive energy reimbursement.

- Negative series modern-day reimbursement / voltage.

Passive filter out is a mixture of resistance, inductance, and capacitance factors and tuned to a particular harmonic frequency manipulate.

\section{PROPOSED SYSTEM \& RESULTS}

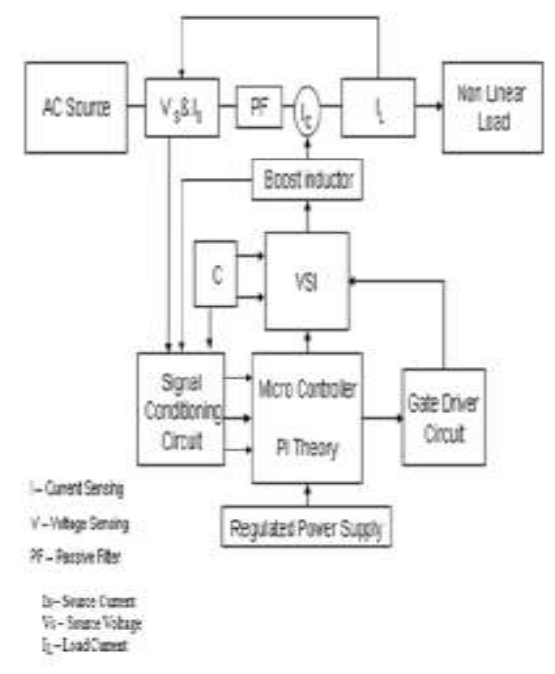

Figure 3: Block Dingram of the Propesed Filter Tzit

In this paper we deal with reactive strength reimbursement using PWMVSI shunt energetic filter with a passive clear out to dispose of harmonics.

Voltage Source Inverter

IRF840 MOSFETs used right here (figure.Four). Inverter Used here is a voltage supply inverter, that is used to update the deliver from the capacitor to the distribution channels. It also consists of anti-parallel diodes linked to the inner of the MOSFET will charge the capacitor to the supply voltage. Switching speeds depending at the pulses generated through ds PIC microcontroller based on the values acquired for the moment repayment. Turn off time of 90ns. The voltage stored inside the capacitor is discharged to a supply line through this inverter circuit. Capacitors in flip charged through the diode is attached anti-parallel to the MOSFET chip.

Because of the nonlinear load modern-day waveform will get distorted with the aid of harmonics, with a view to take away the harmonic currents we inject the identical cost of the modern-day with the assist of dc inverter and a garage capacitor. Toll transfer to the MOSFET gate supplied by means of the compensator calculates dsPIC30F2010 presently. Then fed to the gate as pulses thru the gate driving force circuit. Each diagonal pair do only for a $1 / 2$ cycle. That MOSFET S1 and S2 for the nice half of cycle and $\mathrm{S} 3$ and $\mathrm{S} 4$ for the duration of the terrible half of cycle. 


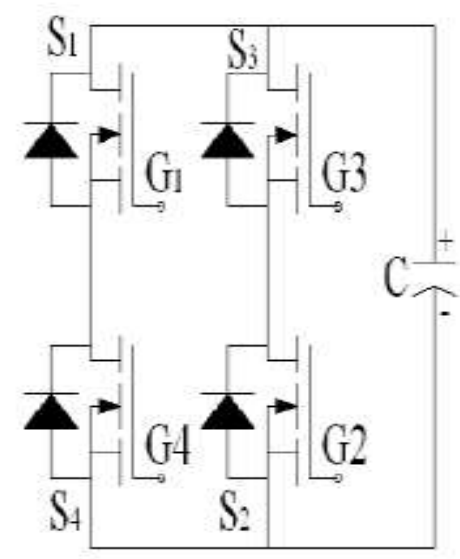

Figure 4: Voltage Source Inverter

At the point when the MOSFET there is a present day infusing course to supply and bad habit versa.We need to comprehend the weight contemporary, the contemporary line to discover that when infusing that it's far redressed. Exactness rectifier square and a poor voltage is utilized to cut zener voltage superior to three.3V. Subsequently, the yield signal obtained after sign molding circuit consistently uni-polar sign zero-3V values well fit with the ADC of the dsPIC30F2010. The yield of the sign molding circuit is nourished to the PIC miniaturized scale controller with the controller will compute the present day compensator. So while infusing determined and VSI accelerated one of these path as to offer some kind of reparation for the consonant flows.

\section{CONCLUSION}

The HAPF mulled over an incredible asset for symphonious limitation and responsive power reimbursement in high-capacity quality channel out. In this paper, in view of the statute of sifting and parameters, the reenactment rendition changed into built up through MATLAB. Thesimulation decision may show a superior presentation than the topology HAPF and oversee procedures.

\section{REFERENCE}

1. "A New Hybrid Active Power Filter for Harmonic Suppression and Reactive Power Compensation", Zhao Wei, LUO A, PENG Jianchun, Deng Xia, PENG to, CICED2008.

2. "An Analysis and Simulation of Shunt Hybrid Active Power Filter", MAYue, Zhu Ling in the Proceedings of the International Conference on Electrical Machines and Systems, 2007.

3. Three. "A Single-Phase Hybrid Active Power Filter the utilization of p-q Extension hypothesis for Photovoltaic Applications", P. C. Tan and Salam Z. Also, A. Jusoh, IEEE peds, 2005.

4. "Plan and Implementation of a Shunt Active Power Filter to Reduce DC hyperlink Voltage", O. Ucak, I. Kocabas, A. Terciyanli 2007.

5. "Structure and Implementation of Hybrid Active Power Filter", G.Nageswara Rao, Dr.K.ChandraSekhar, Dr.P.SangameswaraRaju, International Journal of Computer Applications (0975-8887) Volume eight-10, October2010.
6. "Improved power top notch the utilization of dynamic vitality get out", G.Ravindra, P.Ramesh, Dr.T.Devaraju, InternationalJournal Scientific Research and Publications, Volume 2, Issue 5, May 2012. 